\title{
Mechanical ventilation weaning issues can be counted on the fingers of just one hand: part 2
}

\author{
Luigi Vetrugno $^{1 * \dagger}$, Alessandro Brussa ${ }^{1{ }^{*}+} \mathbb{C}$, Giovanni Maria Guadagnin ${ }^{1}$, Daniele Orso ${ }^{1}$, Francesco De Lorenzo ${ }^{1}$, \\ Gianmaria Cammarota ${ }^{2}$, Erminio Santangelo ${ }^{3}$ and Tiziana Bove ${ }^{1}$
}

\begin{abstract}
Assessing heart and diaphragm function constitutes only one of the steps to consider along the weaning path. In this second part of the review, we will deal with the more systematic evaluation of the pulmonary parenchyma - often implicated in the genesis of respiratory failure. We will also consider the other possible causes of weaning failure that lie beyond the cardio-pulmonary-diaphragmatic system. Finally, we will take a moment to consider the remaining unsolved problems arising from mechanical ventilation and describe the so-called protective approach to parenchyma and diaphragm ventilation.
\end{abstract}

Keywords: Weaning, Mechanical ventilation, Lung ultrasound, Diaphragm dysfunction, Neurally adjusted ventilation assist

\section{Lung ultrasound score (LUS)}

The lung ultrasound (LUS) score is a useful tool that quantifies aerated lung mass and provides real-time information during mechanical ventilation and weaning (Fig. 1) [1]. Specifically, its application in the clinical setting enables optimization of the ventilatory settings in challenging patients by estimating the recruitability of poorly aerated pulmonary mass. This allows clinicians to monitor lung aeration during the weaning process, providing a positive prognostic factor. The LUS score may also help discriminate between a cardiac, parenchymal, or diaphragmatic cause of loss of lung aeration [2] and, in turn, help identify the most appropriate therapeutic approach.

Bouhemad and colleagues (2010) were the first to postulate the potential usefulness of LUS as a tool for monitoring parenchymal reaeration. Their studies

*Correspondence: luigi.vetrugno@uniud.it; alessandro.brussa@gmail.com †'Luigi Vetrugno and Alessandro Brussa contributed equally to this work.

${ }^{1}$ Anesthesiology and Intensive Care Clinic, Department of Medicine,

University of Udine, Via Colugna 50, 33100 Udine, Italy

Full list of author information is available at the end of the article involved assigning a positive or negative score to reflect the change occurring in the parenchymal ultrasound pattern as a result of adjustments to medical antibiotic therapy [3] or positive end-expiratory pressure (PEEP) titration [4]. They found that the degree of lung reaeration could be accurately estimated using the LUS reaeration score. However, use of the LUS score to set ventilatory parameters resulted in the inability to predict lung over-inflation-the physiopathological basis for ventilation-induced lung injury. Soon after, Stefanidis et al. reached the same conclusions in a small pilot study, which once again pointed out the reliability of LUS in evaluating parenchymal reaeration in acute respiratory distress syndrome (ARDS) patients during a PEEP trial [5]. In a more recent, prospective, multicenter study, Haddam et al. analyzed changes in LUS score during the prone positioning of patients with severe ARDS. They revealed that even though the LUS score provides a way to consistently monitor changes in regional lung aeration, it does not correlate with improvements in blood gas oxygenation. A number of reasons may explain this, including a short prone-positioning trial before blood gas 


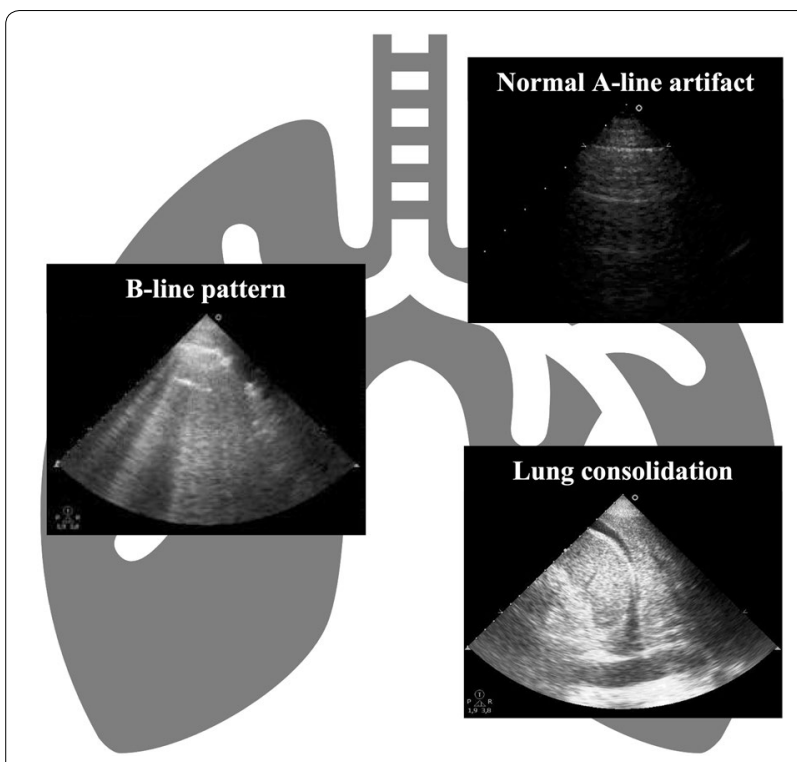

Fig. 1 Different echographic patterns during lung ultrasound evaluation

analysis and a less permissive cut-off in evaluating $\mathrm{PaO}_{2}$ improvements. Nevertheless, Haddam and colleagues underlined the feasibility and utility of LUS evaluation, practically considering it a routine technique [6]. The capacity of LUS to evaluate lung reaeration was also confirmed by Chinardet et al. who used it to estimate lung reaeration following pleural drainage in ARDS patients [7]. However, a recent randomized crossover study by Chiumello et al. found that variations in the LUS score did not correlate with PEEP-induced lung recruitment due to a still inaccurate definition of consolidation pattern [8]. These results could open up a new line of research aimed at increasing the specificity of ultrasound evaluation.

The monitoring of lung aeration during the weaning process embodies another essential aspect of LUS evaluation since it indirectly leads to successful extubation [9]. Clear evidence of the usefulness of the LUS score in the weaning process is provided in the metanalysis by Llamas-Álvarez et al. in which ultrasound evaluation is concluded to provide valuable information in predicting weaning outcome [10]. Tenza-Lozano et al. also came to this conclusion and went on to propose a new and more reproducible score that only considers the anterior, lateral, and posterior-basal thoracic areas [11]. Soummer et al. showed that an LUS score $<13$ after a spontaneous breathing trial (SBT) correlates with successful weaning and safe extubation, whereas a LUS score $>17$ predicts weaning failure with post-extubation respiratory distress [12]. The association between lung de-recruitment and weaning failure was emphasized by Jabaudon et al. who found a loss of aerated lung mass to be the only predictor of weaning failure [13]. In addition to corroborating all of the above, Haji et al. also pointed out the clinical relevance of LUS examination in predicting weaning outcome [14].

The role of LUS as a prognostic factor was first suggested by Frassi et al. [15], who showed that the number of B-lines in an ultrasound evaluation correlated with mortality rate in a cardiac subgroup of patients admitted to hospital with dyspnea or chest pain. Extending this concept, Zhao et al. [16] demonstrated how LUS B-line number could be useful in accurately assessing extravascular lung water in ARDS patients. LUS score also correlates with the lung injury score, the $\mathrm{PaO}_{2} / \mathrm{FiO}_{2}$ ratio, static compliance, and, above all, mortality risk, providing a new and reliable prognostic tool for ARDS patients. More recently, Zou et al. [17] broadened the prognostic value of LUS score to include shock intensive care unit (ICU) patients, and showed that a modified LUS score may act as an independent risk factor for ICU mortality. These data on shock patients were confirmed by Yin et al. [18] in a study involving 175 patients in which the LUS score correlated with 28-day mortality as well as the APACHE II score and lactate serum levels.

Lung ultrasonography, together with its growing role as a prognostic factor, has even been applied in the differential diagnosis of respiratory failure etiology [19]. Jambrik et al. [20] performed the first assessment of extravascular lung water using lung sonography and from these first data LUS has progressed from being the primarily technique to quantify pulmonary interstitial edema, which may derive from different causes, to being developed into a new diagnostic tool for identifying the origin of aerated lung loss. Indeed, over the years, the breadth of application of LUS has expanded, and it is now being applied in the assessment of extravascular lung water in hemodialysis patients [21] and in heart failure patients [22], not to mention the already cited role of the LUS score in predicting a successful SBT $[12,23]$.

Considering all of the above evidence, the critical role of lung ultrasonography and its various applications in the care of critically ill patients becomes highly evident. The role of the anesthesiologist in the management of this powerful tool is thus paramount in order to provide patients with the best medical treatment.

\section{Out of the box}

\section{Neurocritical patients}

Mechanical ventilation is often necessary in brain injury patients (i.e., those suffering from ischemic or hemorrhagic stroke, or severe brain trauma, or metabolic brain injury or resulting from alcohol intoxication, and neurosurgery patients) to prevent aspiration, hypoxemia, 
hypercapnia and further brain injury resulting from reduced/abolished airway protective mechanisms and respiratory drive. Unfortunately, data about mechanical ventilation settings and the weaning process in neurocritical patients are lacking in the literature. A minimal level of arousal should be obtained before weaning and extubation, but neurocritical patients frequently experience prolonged mechanical ventilation periods because of our inability to understand the patient's state of consciousness [24]. The minimal level of arousal necessary to achieve successful extubation also remains controversial. The Glasgow Coma Scale (GCS) has never been validated in intubated patients and, when employed, it has proved to be an inconsistent predictor of successful extubation if used alone [25, 26]. Several scores have been proposed to assess patient arousal, combining airway and neurological statuses, but all lack external validation and often they are not easily applicable at the bedside. In cases of prolonged diminished levels of consciousness, neurocritical patients may never undergo the weaning process, and tracheostomy is commonly employed in the management of these patients, but the timing of this procedure is controversial. Prolonged invasive mechanical ventilation (IMV) in this category of patients can lead to higher rates of ventilator-acquired pneumonia, increased ICU length of stay, and higher mortality rates [24, 25, 27] compared with non-neurological critically ill patients [28].

\section{Intra-abdominal hypertension (IAH)}

Intra-abdominal hypertension (IAH) is defined as an abdominal pressure that exceeds $12 \mathrm{mmHg}$ in at least three consecutive assessments performed within a time window of 4-6 h. Abdominal hypertension can transform into abdominal compartment syndrome (ACS) when intra-abdominal pressure (IAP) reaches values above $20 \mathrm{mmHg}$ with associated single or multiple organ dysfunction/failure [29].

The prevalence of IAH varies in the literature according to the different patient populations studied; it stands at around $54 \%$ in medical ICU patients, $65 \%$ in surgical ICU patients, and $32 \%$ in combined medical-surgical ICU patients [30, 31]. IAH is a serious problem that can produce adverse effects involving both abdominal (i.e., bowel, kidney) and extra-abdominal (i.e., cardiovascular, respiratory) organs, and it is recognized as an independent indicator of mortality in critically ill patients [32].

Primary causes of IAH (i.e., pneumoperitoneum, hemoperitoneum, abdominal trauma, pancreatitis, liver transplantation) can lead to ARDS, and primary ARDS may develop into IAH. The primary mechanical effects through which IAH affects respiratory function are a decreased compliance of the thoracic-pulmonary system and an upward displacement of the diaphragm's starting position [33]. As the lower inflection point of the pressure-volume curve shifts to the right, alveolar opening pressure and inspiratory pressures are also increased [33]. All these elements cause an increased respiratory workload for the spontaneously breathing patient, a compensatory increase in frequency, and, if prolonged, muscle exhaustion (Fig. 2). As a result of reduced inspiratory flow and compression of the lung parenchyma, the dependent areas of the lung will tend toward atelectasis [33]. Subsequently, the continued presence of IAH generates secondary acute lung injury [33], i.e., barotrauma, linked to the increase in peak and plateau pressure in the respiratory tract with the activation of a neutrophilic immune response [33]. Atelectasis may trigger the development of pneumonia [33].

Despite some disputes in literature about the effects of mechanical ventilation and PEEP on IAP, ARDS combined with mechanical ventilation is a known risk factor for intra-abdominal hypertension. The use of PEEP
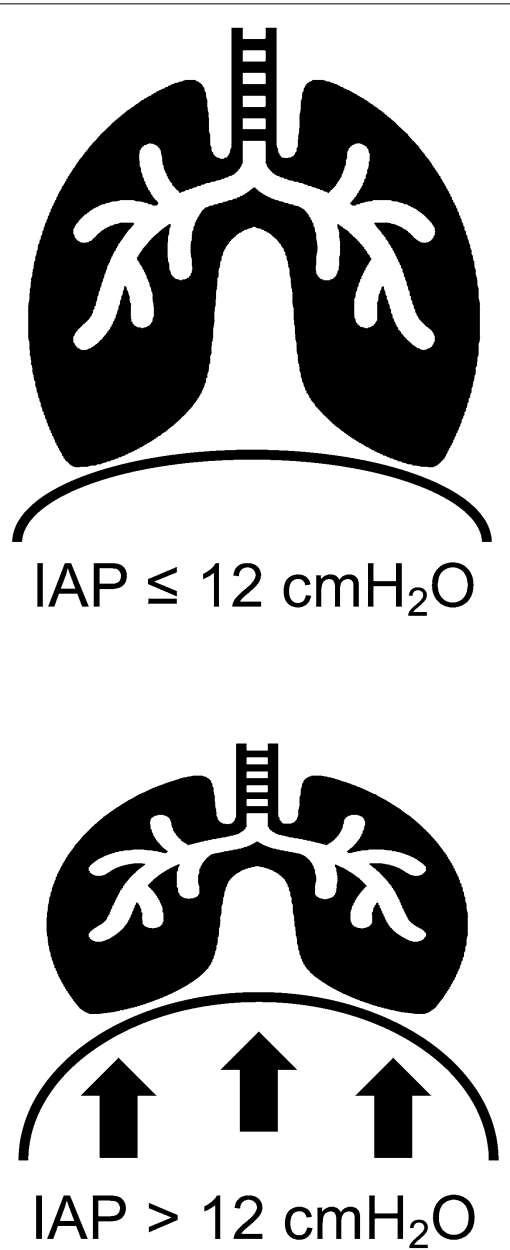

Fig. 2 Effect of intra-abdominal pressure on diaphragmatic dome. IAP intra-abdominal pressure 
increases alveolar recruitment, in turn, increasing residual functional capacity and oxygenation [34], although it causes a flattening of the diaphragmatic dome and a shift to the right side of the pressure-volume curve with the applied pressure being subsequently directed to the abdominal cavity [35]. As such, PEEP should be employed with caution in ARDS patients with IAH, also because moderate PEEP levels can increase IAP and significantly decrease abdominal perfusion pressure proportionally to the PEEP applied [36].

Given the interdependence of the thoracic and abdominal cavities, it is unsurprising that weaning from mechanical ventilation can be particularly difficult in the presence of IAH [37]. We suggest, therefore, in agreement with various other publications and international recommendations, that IAP is closely monitored in mechanically ventilated patients with ARDS.

\section{Pleural effusion}

Pleural effusion (PLEFF) is common in the ICU, although the incidence varies according to the diagnostic technique being used ( $8 \%$ to $60 \%$ ) [38]. However, its role in weaning failure has never been demonstrated-even though the amount of PLEFF is known to influence diaphragm force [39], but this has never been considered in the context of weaning. PLEFF can exacerbate gas exchange, respiratory dynamics, and hemodynamic stability, whereas pleural drainage can improve oxygenation and respiratory mechanics (Fig. 3). At the time of this review, doubts persist about the effectiveness of pleural drainage. In a previous publication, we addressed the effectiveness of ultrasound-guided placement of a small-bore pleural drain for improving patient respiratory gas exchange in terms of the $\mathrm{PaO}_{2} / \mathrm{FiO}_{2}$ ratio, but

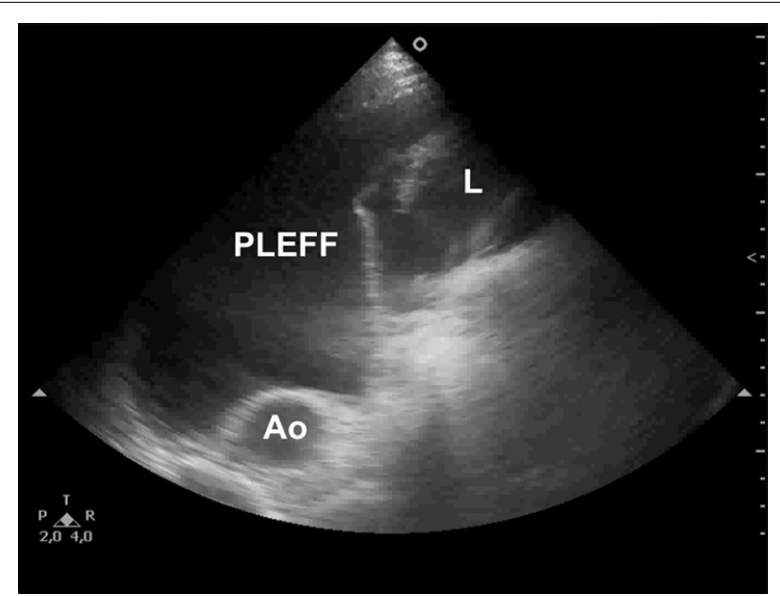

Fig. 3 Massive left-sided pleural effusion with floating fibrin deposition. PLEFF pleural effusion, Ao aorta, L lung no correlation with the maintenance of spontaneous breathing or with weaning from mechanical ventilation was found, in agreement with the work by Dres et al. [40]. These results support the concept that PLEFF cannot constitute the sole parameter being considered when weaning a patient from the ventilator. However, the inconsistency in PLEFF estimations obtained using ultrasound necessitates the need to standardize the methods used for assessing pleural effusion volume (an issue that is overlooked in the current international recommendations on lung ultrasound) [41, 42]. That said, PLEFF drainage also provides the opportunity to obtain chemical-physical and cytological samples to guide the differential diagnosis of PLEFF and any follow-up therapy.

\section{Mechanical ventilation: unsolved issues and possible solutions}

Mechanical ventilation itself may cause lung, heart, and diaphragm dysfunction (Table 1). The mechanisms underlying these types of alterations are not entirely known. The concept of lung and heart protection during mechanical ventilation is better established, whereas a significant gap exists in the literature regarding diaphragm protection. In fact, while specific protocols of lung-protective ventilation are available, the diaphragm is very often neglected, despite the fact that it constitutes the primary actor in physiological respiration.

\section{Ventilator-induced lung injury (VILI)}

The literature is rich with evidence and explanations regarding how mechanical ventilation can cause lung injury. Excessive pressure (barotrauma) or volume (volutrauma) and cyclic alveolar opening-closing (atelectotrauma) are the components that cause ventilator-induced lung injury (VILI) [43]. The effects of all three mechanisms occur under the broader term of "biotrauma", which defines the inflammatory process that follows the initial injury [44]. Specifically, ventilation pressure and induced tidal volume are closely interconnected in the genesis of parenchymal Table 1 Benefits and risks deriving from invasive
mechanical ventilation

\begin{tabular}{ll}
\hline Benefits & Risks \\
\hline Organ support during acute respiratory illness & VILI \\
Protective ventilation protocols & VIDD \\
& Overassistance \\
& Oversedation \\
\hline
\end{tabular}

VILI ventilation-induced lung injury, VAP ventilator-acquired pneumonia, VIDD ventilator-induced diaphragm dysfunction 
damage. Barotrauma is due to excessive stress applied to the lung, directly proportional to the transpulmonary pressure, while volutrauma is secondary to an excessive parenchymal strain, correlated to the tidal volume [45]. In other words, harmful levels of pressure and volume are the two sides of the same coin. Atelectotrauma refers to the continuous opening and closure of potentially recruitable alveoli, which, mainly due to the poor distribution of the pulmonary surfactant, tend to open in response to increasing pressures during the inspiratory phase and to close in the expiratory phase, in accordance with Laplace's law [46]. In the long run, this mechanism triggers the inflammatory process and progressive alveolar atelectasis.

More recent observations regarding IMV have also considered respiratory flow and frequency among the possible determinants of lung injury. As for the aforementioned relationship between volume and pressure, once again, lung injury can derive from the interdependence between inspiratory flow and respiratory rate. To explain this complicated process in more simple terms: the inspiratory flow conveys a given tidal volume based on the pressure delivered in a unit of time, which is, in turn, determined by the respiratory rate and the I:E ratio (inspiration:expiration ratio). The higher the respiratory rate, the lower the inspiratory time and the higher the flow, resulting in greater pressure applied to the lung parenchyma and an increased risk of VILI [47].

From the fifth day of IMV onward, the risk of ventilator-associated pneumonia increases and its presence is correlated with increased morbidity and mortality [48].

\section{Ventilator-induced diaphragm dysfunction}

Mechanical ventilation may also lead to a "...loss of diaphragmatic force-generating capacity" [49], causing ventilator-induced diaphragm dysfunction (VIDD) [49] —an underdiagnosed condition in clinical practice. The causes of this type of diaphragmatic weakness may be prolonged inactivity during mandatory or assisted mechanical ventilation (underloading, i.e., due to the use of myorelaxants or excessive positive pressure support) or an excessive workload (overloading; i.e., due to ventilator asynchrony or inadequate pressure support) [50-53]. Diaphragmatic weakness in critically ill patients in the ICU may also form part of a more general picture of acquired myopathy or polyneuropathy associated with critical illness, or it may present as a single dysfunction in patients who otherwise present no signs of multiple district involvement [54]. Histological changes (oxidative stress and proteolysis phenomena) characterize the pathophysiology of VIDD, which ultimately lead to muscle atrophy [55].

\section{Searching for more protective ventilation}

The demonstration that intrinsic damage resulted from mechanical ventilation led to the development of ventilation protocols able to prevent or at least minimize the damage caused by positive pressure ventilation. The search for improved ventilatory protocols commenced at the beginning of the 2000s, with ARDS patients in mind in particular, and it was then that the term protective ventilation was first coined. Protective ventilation initially involved a reduction in the tidal volume, an adjustment of the PEEP values to ensure the highest possible pulmonary recruitment, and a plateau pressure limit set at $30 \mathrm{~cm} \mathrm{H}_{2} \mathrm{O}$ [56]. Given the clinical relevance of protective ventilation, it was soon extended to the management of mechanical ventilation in the operating room. The daily application of these principles has led to the continuous refinement of lung parenchyma protection protocols-developing the concept of best PEEP, permissive hypercapnia, lung recruitment maneuvers, and, above all, driving pressure [57]. Despite the significant physiopathological rationale, standard protocols for protective ventilation have yet to be identified, mainly due to the ambiguity of the scientific literature [58].

Pressure support ventilation (PSV) is more efficient in limiting ventilator-induced diaphragmatic dysfunction compared with continuous mandatory ventilation (CMV) provided that an adequate level of support pressure and synchronization with the ventilator are maintained [52, 59]. Recently, neurally adjusted ventilator assist $\left(\mathrm{NAVA}^{\circledR}\right)$ has been introduced as a more "physiological" ventilation method that is, at least potentially, able to prevent both overload and disuse atrophy of to the diaphragm allowing early weaning [60]. NAVA delivers assistance in proportion to and in synchrony with the patient's respiratory efforts, measured as the electrical activity of the diaphragm (EAdi). In this way, it is possible to monitor the force generated by the diaphragm, which is inversely proportional to the amplitude of the electrical stimulus necessary for its contraction [61]. Di Mussi and colleagues, in a recent randomized study on patients in the ICU, compared NAVA with PSV [62]. All the diaphragmatic efficiency indexes, such as the pressure-time produced by the diaphragm, were higher in the group of patients receiving NAVA. Furthermore, episodes of asynchrony were more frequent in the PSV group.

NAVA has the advantage of improving patient-ventilator interaction, synchrony, and diaphragm contractile efficiency [52, 62, 63]; however, the neural component of ventilator-induced diaphragmatic dysfunction remains to be fully understood. Further studies are thus needed to elucidate the mechanisms involved in VIDD with the ultimate aim of developing more effective weaning strategies. 


\section{Conclusion}

The ideal time and conditions for achieving successful weaning from mechanical ventilation are a hotly debated topic. As such, weaning remains a non-standardized process and an ever growing proportion of the related literature is focused on trying to identify predictive factors. A complete understanding of the underlying mechanisms responsible for weaning failure is still far from being elucidated. Numerous studies are focused on searching for the individual components involved in respiratory function that may determine weaning failure. Progress has been made though, in particular, thanks to the increasing use of ultrasound that provides real-time in vivo visualization of these components and a form of quantification.

With so many questions about the weaning process remaining open, the purpose of this two-part review was to provide a $360^{\circ}$ view of this critical procedure, one that observes the integrated vision of both respiratory function and the most state-of-the-art predictive indexes available to date.

\begin{abstract}
Abbreviations
LUS: Lung ultrasound; IMV: Invasive mechanical ventilation; ARDS: Acute respiratory distress syndrome; PEEP: Positive end-expiratory pressure; ICU: Intensive care unit; SBT: Spontaneous breathing trial; GCS: Glasgow Coma Scale; IAH: Intra-abdominal hypertension; IAP: Intra-abdominal pressure; PLEFF: Pleural effusion; VILI: Ventilator-induced lung injury; VIDD: Ventilator-induced diaphragm disfunction; PSV: Pressure support ventilation; EAdi: Electrical activity of the diaphragm; NAVA: Neurally adjusted ventilator assist.
\end{abstract}

\section{Acknowledgements}

None.

\section{Authors' contributions}

LV, GMG and AB contributed equally in writing this manuscript. All authors read and approved the final manuscript.

\section{Funding}

This research did not receive any specific grant from funding agencies in the public, commercial, or not-for-profit sectors.

\section{Availability of data and materials}

Not applicable.

\section{Ethics approval and consent to participate}

Not applicable.

\section{Consent for publication}

Informed consent for publication of completely anonymous data was obtained from the patients at the hospital admission.

\section{Competing interests}

Luigi Vetrugno receives fee and travel support for Congress Lecture by Cook Medical. The authors declare that they have no competing interests.

\footnotetext{
Author details

${ }^{1}$ Anesthesiology and Intensive Care Clinic, Department of Medicine, University of Udine, Via Colugna 50, 33100 Udine, Italy. ${ }^{2}$ Department of Anesthesiology and Intensive Care, Maggiore della Carità University Hospital, Corso Mazzini 18, 28100 Novara, Italy. ${ }^{3}$ Department of Translational Medicine, University of Eastern Piemonte, via Solaroli, 17, 28100 Novara, Italy.
}

Received: 25 November 2019 Accepted: 6 February 2020

Published online: 13 March 2020

\section{References}

1. Bouhemad B, Mongodi S, Via G, Rouquette I (2015) Ultrasound for "lung monitoring" of ventilated patients. Anesthesiology 122:437-447. https:// doi.org/10.1097/ALN.0000000000000558

2. Via G, Storti E, Gulati G, Neri L, Mojoli F, Braschi A (2012) Lung ultrasound in the ICU: from diagnostic instrument to respiratory monitoring tool. Minerva Anestesiol 78:1282-1296

3. Bouhemad B, Liu ZH, Arbelot C, Zhang M, Ferarri F, Le-Guen M, Girard M, Lu Q, Rouby JJ (2010) Ultrasound assessment of antibiotic-induced pulmonary reaeration in ventilator-associated pneumonia. Crit Care Med 38:84-92. https://doi.org/10.1097/CCM.0b013e3181b08cdb

4. Bouhemad B, Brisson H, Le-Guen M, Arbelot C, Lu Q, Rouby JJ (2011) Bedside ultrasound assessment of positive end-expiratory pressure-induced lung recruitment. Am J Respir Crit Care Med 183:341-347. https://doi. org/10.1164/rccm.201003-03690C

5. Stefanidis K, Dimopoulos S, Tripodaki ES, Vitzilaios K, Politis P, Piperopoulos P, Nanas S (2011) Lung sonography and recruitment in patients with early acute respiratory distress syndrome: a pilot study. Crit Care 15:R185. https://doi.org/10.1186/cc10338

6. Haddam M, Zieleskiewicz L, Perbet S, Baldovini A, Guervilly C, Arbelot C, Noel A, Vigne C, Hammad E, Antonini F, Lehingue S, Peytel E, Lu Q, Bouhemad B, Golmard JL, Langeron O, Martin C, Muller L, Rouby JJ, Constantin JM, Papazian L, Leone M, CAR'Echo Collaborative Network; AzuRea Collaborative Network (2016) Lung ultrasonography for assessment of oxygenation response to prone position ventilation in ARDS. Intensive Care Med 42:1546-1556. https://doi.org/10.1007/s00134-016-4411-7

7. Chinardet B, Brisson H, Arbelot C, Langeron O, Rouby JJ, Lu Q (2016) Ultrasound assessment of lung consolidation and reaeration after pleural effusion drainage in patients with acute respiratory distress syndrome: a pilot study. Acta Anaesthesiol Belg 67:29-35

8. Chiumello D, Mongodi S, Algieri I, Vergani GL, Orlando A, Via G, Crimella F, Cressoni M, Mojoli F (2018) Assessment of lung aeration and recruitment by $C T$ scan and ultrasound in acute respiratory distress syndrome patients. Crit Care Med 46:1761-1768. https://doi.org/10.1097/ CCM.0000000000003340

9. Bouhemad B, Mojoli F, Nowobilski N, Hussain A, Rouquette I, Guinot PG, Mongodi S (2020) Use of combined cardiac and lung ultrasound to predict weaning failure in elderly, high-risk cardiac patients: a pilot study. Intensive Care Med. https://doi.org/10.1007/s00134-019-05902-9

10. Llamas-Álvarez AM, Tenza-Lozano EM, Latour-Pérez J (2017) Diaphragm and lung ultrasound to predict weaning outcome: systematic review and meta-analysis. Chest 152:1140-1150. https://doi.org/10.1016/j.chest .2017.08.028

11. Tenza-Lozano E, Llamas-Álvarez AM, Jaimez-Navarro E, FernandezSanchez J (2018) Lung and diaphragm ultrasound as predictors of success in weaning from mechanical ventilation. Crit Ultrasound J 10:12. https://doi.org/10.1186/s13089-018-0094-3

12. Soummer A, Perbet S, Brisson H, Arbelot C, Constantin JM, Lu Q, Rouby $J$ J, Lung Ultrasound Study Group (2012) Ultrasound assessment of lung aeration loss during a successful weaning trial predicts postextubation distress. Crit Care Med 40:2064-2072. https://doi.org/10.1097/CCM.0b013 e31824e68ae

13. Jabaudon $M$, Perbet $S$, Pereira $B$, Soummer A, Roszyk L, Guérin R, Futier E, Lu Q, Bazin JE, Sapin V, Rouby JJ, Constantin JM (2013) Plasma levels of sRAGE, loss of aeration and weaning failure in ICU patients: a prospective observational multicenter study. PLoS ONE 8:e64083. https://doi. org/10.1371/journal.pone.0064083

14. Haji K, Haji D, Canty DJ, Royse AG, Green C, Royse CF (2018) The impact of heart, lung and diaphragmatic ultrasound on prediction of failed extubation from mechanical ventilation in critically ill patients: a prospective observational pilot study. Crit Ultrasound J 10:13. https://doi.org/10.1186/ s13089-018-0096-1

15. Frassi F, Gargani L, Tesorio P, Raciti M, Mottola G, Picano E (2007) Prognostic value of extravascular lung water assessed with ultrasound lung comets by chest sonography in patients with dyspnea and/or chest pain. J Card Fail 13:830-835. https://doi.org/10.1016/j.cardfail.2007.07.003 
16. Zhao Z, Jiang L, Xi X, Jiang Q, Zhu B, Wang M, Xing J, Zhang D (2015) Prognostic value of extravascular lung water assessed with lung ultrasound score by chest sonography in patients with acute respiratory distress syndrome. BMC Pulm Med 15:98. https://doi.org/10.1186/s1289 0-015-0091-2

17. Zou TJ, Yin MG, Qin Y, Li Y, Zeng XY, Kang Y (2017) Prognostic value of modified lung ultrasound aeration loss score in shock patient in intensive care unit. Zhonghua Yi Xue Za Zhi. 97:2244-2247. https://doi. org/10.3760/cma.jissn.0376-2491.2017.29.002

18. Yin W, Zou T, Qin Y, Yang J, Li Y, Zeng X, Kang Y, Chinese Critical Ultrasound Study Group (CCUSG) (2019) Poor lung ultrasound score in shock patients admitted to the ICU is associated with worse outcome. BMC Pulm Med 19:1. https://doi.org/10.1186/s12890-018-0755-9

19. Lichtenstein DA, Meziere GA (2008) Relevance of lung ultrasound in the diagnosis of acute respiratory failure: the BLUE protocol. Chest 134:117-125. https://doi.org/10.1378/chest.07-2800

20. Jambrik Z, Monti S, Coppola V, Aqricola E, Mottola G, Miniati M (2004) Usefulness of ultrasound lung comets as a nonradiologic sign of extravascular lung water. Am J Cardiol 93:1265-1270. https://doi.org/10.1016/j. amjcard.2004.02.012

21. Noble VE, Murray AF, Capp R, Syivia-Reardon MH, Steele DJ, Liteplo A (2009) Ultrasound assessment for extravascular lung water in patients undergoing hemodialysis. Time course for resolution. Chest 135:14331439. https://doi.org/10.1378/chest.08-1811

22. Agricola E, Bove T, Oppizzi M, Marino G, Zangrillo A, Margonato A, Picano E (2005) "Ultrasound comet-tail images": a marker of pulmonary edema: a comparative study with wedge pressure and extravascular lung water. Chest 127:1690-1695. https://doi.org/10.1378/chest.127.5.1690

23. Silva S, Ait Aissa D, Cocquet P, Hoarau L, Ruiz J, Ferre F, Rousset D, Mora M, Mari A, Fourcade O, Riu B, Jaber S, Bataille B (2017) Combined thoracic ultrasound assessment during a successful weaning trial predicts postextubation distress. Anesthesiology 127:666-674. https://doi.org/10.1097/ ALN.00000000000001773

24. Coplin WM, Pierson DJ, Cooley KD, Newell DW, Rubenfeld GD (2000) Implications of extubation delay in brain-injured patients meeting standard weaning criteria. Am J Respir Crit Care Med 161:1530-1536. https:// doi.org/10.1164/ajrccm.161.5.9905102

25. Godet T, Chabanne R, Marin J, Kauffmann S, Futier E, Pereira B, Constantin JM (2017) Extubation failure in brain-injured patients: risk factors and development of a prediction score in a preliminary prospective cohort study. Anesthesiology 126:104-114. https://doi.org/10.1097/ALN.00000 00000001379

26. McCredie VA, Ferguson ND, Pinto RL, Adhikari NK, Fowler RA, Chapman MG, Burrell A, Baker AJ, Cook DJ, Meade MO, Scales DC, Canadian Critical Care Trials Group (2017) Airway management strategies for brain-injured patients meeting standard criteria to consider extubation. A prospective cohort study. Ann Am Thorac Soc 14:85-93. https://doi.org/10.1513/ AnnalsATS.201608-6200C

27. Asehnoune K, Seguin P, Lasocki S, Roquilly A, Delater A, Gros A, Denou F, Mahé PJ, Nesseler N, Demeure-Dit-Latte D, Launey Y, Lakhal K, Rozec B, Mallédant Y, Sébille V, Jaber S, Le Thuaut A, Feuillet F, Cinotti R, ATLANREA group (2017) Extubation success prediction in a multicentric cohort of patients with severe brain injury. Anesthesiology 127:338-346. https:// doi.org/10.1097/ALN.0000000000001725

28. Pelosi P, Ferguson ND, Frutos-Vivar F, Anzueto A, Putensen C, Raymondos K, Apezteguia C, Desmery P, Hurtado J, Abroug F, Elizalde J, Tomicic V, Cakar N, Gonzalez M, Arabi Y, Moreno R, Esteban A, for the Ventila Study Group (2011) Management and outcome of mechanically ventilated neurologic patients. Crit Care Med 39:1482-1492. https://doi.org/10.1097/ CCM.0b013e31821209a8

29. Kirkpatrick AW, Sugrue M, McKee JL, Pereira BM, Roberts DJ, De Waele JJ, Leppaniemi A, Ejike JC, Reintam Blaser A, D'Amours S, De Keulenaer B, Malbrain MLNG (2017) Update from the abdominal compartment society (WSACS) on intra-abdominal hypertension and abdominal compartment syndrome: past, present, and future beyond Banff 2017. Anaesthesiol Intensive Ther 49:83-87. https://doi.org/10.5603/AlT.a2017.0019

30. Malbrain ML, Cheatham ML, Kirkpatrick A, Sugrue M, De Waele J, Ivatury $R$ (2006) Abdominal compartment syndrome: it's time to pay attention! Intensive Care Med 32:1912-1914. https://doi.org/10.1007/s0013 4-006-0303-6
31. Malbrain ML, Chiumello D, Pelosi P, Bihari D, Innes R, Ranieri VM (2005) Incidence and prognosis of intraabdominal hypertension in a mixed population of critically ill patients: a multiple-center epidemiological study. Crit Care Med 33:315-322. https://doi.org/10.1097/01.ccm.00001 53408.09806.1 b

32. Cheatham ML, Safcsak K (2010) Is the evolving management of intraabdominal hypertension and abdominal compartment syndrome improving survival? Crit Care Med 38:402-407. https://doi.org/10.1097/ ccm.0b013e3181b9e9b1

33. Pelosi P, Quintel M, Malbrain ML (2007) Effect of intra-abdominal pressure on respiratory mechanics. Acta Clin Belg Suppl 1:78-88

34. Gattinoni L, Carlesso E, Brazzi L, Caironi P (2010) Positive end expiratory pressure. Curr Opin Crit Care 16:39-44. https://doi.org/10.1097/ MCC.0b013e3283354723

35. Malbrain ML, DeWaele J (2013) Intra-abdominal Hypertension. Cambridge University Press, Cambridge

36. Verzilii D, Constantin JM, Sebbane M, Chanques G, Jung B, Perrigault PF, Malbrain ML, Jaber S (2010) Positive end expiratory pressure effects the value of intra-abdominal pressure in acute lung injury/acute respiratory distress syndrome patients: a pilot study. Crit Care 14:137-142. https:// doi.org/10.1186/cc9193

37. Murtaza G, Inam PI KM, Nawaz Jajja MR, Nawaz Z, Koondhar R, Nasim S (2015) Intra abdominal hypertension; incidence, prevalence and outcomes in a mixed intensive care unit: prospective cohort study. Int J Surg 19:67-71. https://doi.org/10.1016/j.ijsu.2015.05.014

38. Brogi E, Gargani L, Bignami E, Barbariol F, Marra A, Forfori F, Vetrugno L (2017) Thoracic ultrasound for pleural effusion in the intensive care unit: a narrative review from diagnosis to treatment. Crit Care 21:325. https://doi. org/10.1186/s13054-017-1897-5

39. Vetrugno L, Bignami E, Orso D, Vargas M, Guadagnin GM, Saglietti F, Servillo G, Volpicelli G, Navalesi P, Bove T (2019) Utility of pleural effusion drainage in the ICU: an updated systematic review and META-analysis. J Crit Care 52:22-32. https://doi.org/10.1016/.j.crc.2019.03.007

40. Dres M, Roux D, Pham T, Beurton A, Ricard JD, Fartoukh M, Demoule A (2017) Prevalence and impact on weaning of pleural effusion at the time of liberation from mechanical ventilation: a multicenter prospective observational study. Anesthesiology 126(6):1107-1115. https://doi. org/10.1097/ALN.0000000000001621

41. Vetrugno L, Guadagnin GM, Barbariol F, D'Incà S, Delrio S, Orso D, Girometti R, Volpicelli G, Bove T (2019) Assessment of pleural effusion and small pleural drain insertion by resident doctors in an intensive care unit: an observational study. Clin Med Insights Circ Respir Pulm Med 13:1179548419871527. https://doi.org/10.1177/1179548419871527

42. Vetrugno L, Guadagnin GM, Orso D, Boero E, Bignami E, Bove T (2018) An easier and safe affair, pleural drainage with ultrasound in critical patient: a technical note. Crit Ultrasound J. 10:18. https://doi.org/10.1186/s1308 9-018-0098-z

43. Albert RK (2012) The role of ventilation-induced surfactant dysfunction and atelectasis in causing acute respiratory distress syndrome. Am J Respir Crit Care Med 185:702-708. https://doi.org/10.1164/rccm.20110 9-1667PP

44. Tremblay LN, Slutsky AS (1998) Ventilator-induced injury: from barotrauma to biotrauma. Proc Assoc Am Physicians 110:482-488

45. Parker JC, Hernandez LA, Peevy KJ (1993) Mechanisms of ventilator-induced lung injury. Crit Care Med 21:131-143. https://doi. org/10.1097/00003246-199301000-00024

46. Taskar V, John J, Evander E, Robertson B, Jonson B (1997) Surfactant dysfunction makes lungs vulnerable to repetitive collapse and reexpansion. Am J Respir Crit Care Med 155:313-320. https://doi.org/10.1164/ajrcc m.155.1.9001330

47. Tonetti T, Vasques F, Rapetti F, Maiolo G, Collino F, Romitti F, Camporota L, Cressoni M, Cadringher P, Quintel M, Gattinoni L (2017) Driving pressure and mechanical power: new targets for VILI prevention. Ann Transl Med. 5:286. https://doi.org/10.21037/atm.2017.07.08

48. Heyland DK, Cook DJ, Griffith L, Keenan SP, Brun-Buisson C (1999) The attributable morbidity and mortality of ventilator associated pneumonia in the critically ill patient. The canadian critical care trials group. Am J Respir Crit Care Med 159:1249-1256. https://doi.org/10.1164/ajrcc m.159.4.9807050 
49. Vassilakopoulos T, Petrof BJ (2004) Ventilator-induced diaphragmatic dysfunction. Am J Respir Crit Care Med 169:336-341. https://doi. org/10.1164/rccm.200304-489CP

50. Cammarota G, Sguazzotti I, Zanoni M, Messina A, Colombo D, Vignazia GL, Vetrugno L, Garofalo E, Bruni A, Navalesi P, Avanzi GC, Della Corte F, Volpicelli G, Vaschetto R (2019) Diaphragmatic ultrasound assessment in subjects with acute hypercapnic respiratory failure admitted to the emergency department. Respir Care 64:1469-1477. https://doi.org/10.4187/ respcare.06803

51. Goligher EC, Dres M, Fan E, Rubenfeld GD, Scales DC, Herridge MS, Vorona S, Sklar MC, Rittayamai N, Lanys A, Murray A, Brace D, Urrea C, Reid WD, Tomlinson G, Slutsky AS, Kavanagh BP, Brochard LJ, Ferguson ND (2018) Mechanical ventilation-induced diaphragm atrophy strongly impacts clinical outcomes. Am J Respir Crit Care Med 197:204-213. https://doi. org/10.1164/rccm.201703-05360C

52. Bruni A, Garofalo E, Pelaia C, Messina A, Cammarota G, Murabito P, Corrado S, Vetrugno L, Longhini F, Navalesi P (2019) Patient-ventilator asynchrony in adult critically ill patients. Minerva Anestesiol 85:676-688 https://doi.org/10.23736/S0375-9393.19.13436-0

53. Vetrugno L, Guadagnin GM, Barbariol F, Langiano N, Zangrillo A, Bove T (2019) Ultrasound imaging for diaphragm dysfunction: a narrative literature review. J Cardiothorac Vasc Anesth 33:2525-2536. https://doi. org/10.1053/j.jvca.2019.01.003

54. Santos PD, Teixeira C, Savi A, Maccari JG, Neres FS, Machado AS, de Oliveira RP, Ribeiro M, Rotta FT (2012) The critical illness polyneuropathy in septic patients with prolonged weaning from mechanical ventilation: is the diaphragm also affected? A pilot study. Respir Care 57:1594. https:// doi.org/10.4187/respcare.01396

55. Levine S, Nguyen T, Taylor N, Friscia ME, Budak MT, Rothenberg P, Zhu J, Sachdeva R, Sonnad S, Kaiser LR, Rubinstein NA, Powers SK, Shrager JB (2008) Rapid disuse atrophy of diaphragm fibers in mechanically ventilated humans. N Engl J Med 358:1327-1335. https://doi.org/10.1056/ NEJMoa070447

56. Network The Acute Respiratory Distress Syndrome, Brower RG, Matthay MA, Morris A, Schoenfeld D, Thompson BT, Wheeler A (2000) Ventilation with lower tidal volumes as compared with traditional tidal volumes for acute lung injury and the acute respiratory distress syndrome. N Engl J Med 342:1301-1308. https://doi.org/10.1056/NEJM200005043421801

57. Neto AS, Hemmes SN, Barbas CS, Beiderlinden M, Fernandez-Bustamante A, Futier E, Gajic O, El-Tahan MR, Ghamdi AA, Günay E, Jaber S, Kokulu S, Kozian A, Licker M, Lin WQ, Maslow AD, Memtsoudis SG, Reis Miranda D, Moine P, Ng T, Paparella D, Ranieri VM, Scavonetto F, Schilling T, Selmo G, Severgnini P, Sprung J, Sundar S, Talmor D, Treschan T, Unzueta C,
Weingarten TN, Wolthuis EK, Wrigge H, Amato MB, Costa EL, de Abreu MG, Pelosi P, Schultz MJ, PROVE Network Investigators (2016) Association between driving pressure and development of postoperative pulmonary complications in patients undergoing mechanical ventilation for general anaesthesia: a meta-analysis of individual patient data. Lancet Respir Med. 4:272-280. https://doi.org/10.1016/\$2213-2600(16)00057-6

58. Writing Group for the Alveolar Recruitment for Acute Respiratory Distress Syndrome Trial (ART) Investigators, Cavalcanti AB, Suzumura ÉA, Laranjeira LN, Paisani DM, Damiani LP, Guimarães HP, Romano ER, Regenga MM, Taniguchi LNT, Teixeira C, Pinheiro de Oliveira R, Machado FR, DiazQuijano FA, Filho MSA, Maia IS, Caser EB, Filho WO, Borges MC, Martins PA, Matsui M, Ospina-Tascón GA, Giancursi TS, Giraldo-Ramirez ND, Vieira SRR, Assef MDGPL, Hasan MS, Szczeklik W, Rios F, Amato MBP, Berwanger O, Ribeiro de Carvalho CR (2017) Effect of lung recruitment and titrated positive end-expiratory pressure (PEEP) vs low PEEP on mortality in patients with acute respiratory distress syndrome: a randomized clinical trial. JAMA 318:1335-1345. https://doi.org/10.1001/jama.2017.14171

59. Hudson MB, Smuder AJ, Nelson WB, Bruells CS, Levine S, Powers SK (2012) Both high level pressure support ventilation and controlled mechanical ventilation induce diaphragm dysfunction and atrophy. Crit Care Med 40:1254-1260. https://doi.org/10.1097/CCM.0b013e31823c8cc9

60. Lamouret O, Crognier L, Vardon Bounes F, Conil JM, Dilasser C, Raimondi T, Ruiz S, Rouget A, Delmas C, Seguin T, Minville V, Georges B (2019) Neurally adjusted ventilator assist (NAVA) versus pressure support ventilation: patient-ventilator interaction during invasive ventilation delivered by tracheostomy. Crit Care 23:2. https://doi.org/10.1 186/s13054-018-2288-2

61. Barwing J, Pedroni C, Olgemöller U, Quintel M, Moerer O (2013) Electrical activity of the diaphragm (EAdi) as a monitoring parameter in difficult weaning from respirator: a pilot study. Crit Care 17:R182. https://doi. org/10.1186/cc12865

62. Di Mussi R, Spadaro S, Mirabella L, Volta CA, Serio G, Staffieri F, Dambrosio M, Cinnella G, Bruno F, Grasso S (2016) Impact of prolonged assisted ventilation on diaphragmatic efficiency: NAVA versus PSV. Crit Care 20:1. https://doi.org/10.1186/s13054-015-1178-0

63. Garofalo E, Bruni A, Pelaia C, Liparota L, Lombardo N, Longhini F, Navalesi P (2018) Recognizing, quantifying and managing patient-ventilator asynchrony in invasive and noninvasive ventilation. Expert Rev Respir Med 12:557-567. https://doi.org/10.1080/17476348.2018.1480941

\section{Publisher's Note}

Springer Nature remains neutral with regard to jurisdictional claims in published maps and institutional affiliations.

\section{Submit your manuscript to a SpringerOpen ${ }^{\circ}$ journal and benefit from:}

- Convenient online submission

- Rigorous peer review

- Open access: articles freely available online

- High visibility within the field

- Retaining the copyright to your article

Submit your next manuscript at $\boldsymbol{\nabla}$ springeropen.com 